EL ÁREA DE LIBRE

COMERCIO

\section{DE LAS AMÉRICAS}

-ALCA-: TAREAS

Y RETOS ANTE

UN PROYECTO

DE INTEGRACIÓN

Luis Enrique

Gamboa Umaña*

\section{RESUMEN}

En el este artículo se estudian las tareas y retos que se presentan alrededor de la conformación del Área de Libre Comercio de las Américas (ALCA). Se hace un breve recorrido histórico de los proyectos hegemónicos de los Esta-

* Catedrático de la UCR, Licenciado en Ciencias de la Educación, Magister Artium en Ciencias Sociales, Máster en Historia y Profesor de la Escuela de Estudios Generales de la UCR. El autor agradece a Henry Mora, Director de la Escuela de Economía de la Universidad Nacional -UNA- y profesor del curso Globalización y Políticas Públicas del Doctorado en Gobierno y Políticas Públicas de la UCR, la asesoría y las recomendaciones bibliográficas que hicieron posible la elaboración de este documento. dos Unidos de América desde la Doctrina Monroe (1823) hasta las recientes Cumbres de Presidentes y las reuniones ministeriales. Se resaltan los orígenes del proyecto como una iniciativa del Gobierno de los Estados Unidos. Se considera la naturaleza de las acciones y se analizan los intereses de los actores estratégicos desplegados en el proceso de negociaciones. Dicho estudio también presenta el método sugerido para analizar el grado de preparación de Costa Rica para participar en el ALCA. Concluye con un análisis de algunas reacciones ante y contra este proyecto de integración.

"El estudio de la economía no tiene por objeto la adquisición de un conjunto de respuestas preparadas para los problemas económicos, sino aprender a no dejarse engañar por los economistas."

JOAN ROBINSON

\section{PRESENTACIÓN}

Hace más de un siglo, frente a la invitación del gobierno de los Estados Unidos de América para crear una unión monetaria entre las repúblicas de América, José Martí (1853-1895), hizo la siguiente advertencia:

"Cuando un pueblo es invitado a unión por otro, podría hacerlo con prisa el estadista ignorante y deslumbrado, podrá celebrarlo sin juicio la juventud prendada de las bellas 
ideas, podrá recibirlo como una merced el político venal o demente, y glorificarlo con palabras serviles; pero el que siente en su corazón la angustia de la patria, el que vigila y prevé, ha de inquirir y ha de decir qué elementos componen el carácter del pueblo que convida y el del convidado, y si es probable o no que los elementos temibles del pueblo invitante se desarrollen en la unión que pretende, con peligro del invitado; ha de inquirir cuáles son las fuerzas políticas del país que le convida, y los intereses de sus partidos, y los intereses de sus hombres, en el momento de la invitación. Y el que resuelva sin investigar, o desee la unión sin conocer, o la recomiende por mera frase y deslumbramiento, o la defienda por la poquedad del alma aldeana, hará mal a América" (Martí, 1991:158, citado por Salgado, 2002).

En la actualidad, las palabras de Martí pueden ser objeto de una lectura atenta, especialmente por parte de los tomadores de decisiones para que vislumbren todos los matices existentes en esta etapa de desarrollo del capitalismo mundializado y los cambios que conllevan la globalidad, el globalismo y la globalización. Los países, y entre ellos Costa Rica, se enfrentan a una nueva estrategia de las potencias capitalistas que llevan a re- plantear el papel de los Estados nacionales y que tiene una profunda incidencia en la formulación de las políticas públicas ${ }^{1}$. Una muestra de esas nuevas estrategias lo constituyen los proyectos de libre comercio entre los cuales destaca el Área de Libre Comercio de las Américas (ALCA). Se trata, entonces, de conocer el proyecto, investigar, parafraseando a Martí, para hacer bien a América, especialmente el subcontinente.

En el presente documento se busca analizar los antecedentes a la conformación de un área de libre comercio en América para luego estudiar los contenidos de ese acuerdo. Interesa también destacar la naturaleza de las negociaciones y

1. Por política pública se entenderá un curso de acción efectuado por una autoridad pública dirigido a la solución de un problema o situación que le concierne (Anderson, 1978). Las políticas públicas son procesos o decisiones que incluyen los conflictos de intereses, las tensiones debidas a las diferentes definiciones de los problemas y diferentes racionalidades, acciones y perspectivas evaluadoras. El contexto de una política pública es un escenario lleno de poderes en conflicto que se enfrentan o colaboran entre opciones y cursos de acción específicos, incluso cuando se decide "no hacer algo" (Lindblom, 1994). Esta noción considera también los aportes teóricos de Subirats (1992) y Meny y Thoening (1992). 
el papel de los actores más destacados. Como parte de un esfuerzo nacional se incluye la discusión sobre el grado de preparación de Costa Rica para el ALCA según una metodología comparativa. Interesa destacar en este documento las reacciones ante y contra el ALCA procedentes de cuatro entornos representativos. Finalmente, se presentan unas conclusiones en las cuales se pretende destacar la inconveniencia de la actual versión del proyecto de libre comercio.

\section{Hacia la conformación de un área de libre comercio en América}

En esta sección se hará un recorrido histórico que abarca el período republicano (o postcolonial) caracterizado por la hegemonía ${ }^{2}$ estadounidense. Se enfatizará en el último decenio del siglo XX y las Cumbres de Presidentes.

2. Entre los teóricos de la hegemonía la actual potencia hegemónica decide el contenido de la información, monopoliza las nuevas tecnologías de la información y los lenguajes computacionales, domina gran parte de los servicios, acoge las centrales de todas o casi todas las grandes multinacionales, tiene en sus manos el mercado mundial, gobierna la educación y los centros de educación superior de excelencia y las
De "América

para los americanos"

al socio (pasando

por el "gran vecino"

y el "buen garrote")

El ALCA es una iniciativa del gobierno de los Estados Unidos de América durante la Administración del presidente George Bush padre (1988-1992). Sin embargo, para mostrar los antecedentes y hábitos comunes (en términos martianos) de la poderosa nación del Norte, es conveniente destacar los siguientes momentos:

- 1823: Doctrina Monroe. Al concluir el dominio colonial español, y cuando apenas los Estados americanos daban sus primeros pasos, el vecino del Norte, mostró su poderío y sus intenciones. El 2 de diciembre de 1823, el presidente de los Estados Unidos, James Monroe (1758-1831), formuló una doctrina que rechazaba la intervención europea en América pero manifestaba a la vez sus intereses específicos. El texto dice:

instituciones de producción de la ciencia, controla los organismos internacionales que imponen las directrices de política económica y aportan recursos a los países en desarrollo (FMI, Banco Mundial), ejerce el dominio de la industria del ocio, impone sus propios valores y homogeneiza los gustos, señala el tipo de civilización que desea (la "occidental") y un largo etcétera. (Ver Vallespín, 2000, 50-51). 
“...los continentes americanos, por la libre e independiente condición que han asumido y que mantienen, no deberán ser considerados ya como susceptibles de futura colonización por cualquiera de las potencias europeas."

"La sinceridad y relaciones amistosas que existen entre los Estados Unidos y aquellas potencias, nos obligan a declarar que consideraríamos peligroso para nuestra paz y seguridad cualquier tentativa de parte de ellas que tenga por objeto extender su sistema a una porción de este hemisferio, sea cual fuere. No hemos intervenido ni intervendremos en las colonias o dependencias de cualquier potencia europea: pero cuando se trate de gobiernos que hayan declarado y mantenido su independencia, y que después de madura consideración, y de acuerdo con justos principios, hayan sido reconocidos como independientes por el gobierno de los Estados Unidos, cualquiera intervención de una potencia europea, con el objeto de oprimirlos o de dirigir de alguna manera sus destinos, no podrá ser vista por nosotros sino como la manifestación de una disposición hostil hacia los Estados Unidos."
En el texto no aparece la referencia a la síntesis de "América para los americanos"; fueron los periodistas quienes lo acuñaron y expresaron lo que en la forma se insinuaba.

- 1826: Congreso convocado por Simón Bolívar (1789-1830) en donde los Estados Unidos obstaculizaron el ideal bolivariano de una Patria Grande.

- 1846 y 1848: guerra de Estados Unidos con México en donde primero se apoderó de Texas y luego de Arizona, Nuevo México, California, Nevada, Utah y parte de Wyoming.

- 1898: Guerra Hispano-Norteamericana en donde Estados Unidos se apoderó de Cuba, Puerto Rico, Filipinas y Guam.

- 1903: Tratado Hay-Bunau Varilla con el cual Estados Unidos logró la separación de la provincia colombiana de Panamá, proclamó la independencia de esa nueva nación y obtuvo de ella la cesión de la Zona del Canal.

- 1904: politica del Big stick (Gran garrote) formulada por Teodoro Roosevelt (1858-1919). Esa política quedó formulada con el siguiente texto:

"Si una nación demuestra saber actuar con una eficacia razonable y con el sentido de las 
conveniencias en materia social y política, si mantiene el orden y respeta sus obligaciones, no tiene porqué temer una intervención de los Estados Unidos. La injusticia crónica o la importancia que resultan de un relajamiento general de las reglas de una sociedad civilizada pueden exigir a fin de cuentas, en América o fuera de ella, la intervención de una nación civilizada y, en el hemisferio occidental, la adhesión de los Estados Unidos a la doctrina de Monroe puede obligar a los Estados Unidos, aunque en contra de sus deseos, en caso flagrantes de injustica o de impotencia, a ejercer un poder de policía internacional."

- 1910: Unión Panamericana y luego "la diplomacia del dólar" bajo el gobierno de Woodrow Wilson (1856-1924).

- Decenio de 1930: política del "Buen vecino" formulada por Franklin Roosevelt (1882-1945) ante la amenaza de la II Guerra Mundial y que fue útil para implementar la Organización de Estados Americanos (OEA) y el Tratado Interamericano de Asistencia Recíproca (TIAR). Con esta política nació el interamericanismo y se impulsó un nuevo expansionismo estadounidense en el subcontinente.
- 1960: La Alianza para el Progreso. Formulada por John F. Kennedy (1917-1963) que planteó una política de ayuda integral para América Latina. Kennedy fue asesinado en circunstancias todavía oscuras.

- Decenio de 1970: apoyo regímenes militaristas y lucha antiguerrillera bajo el liderazgo de Richard Nixon y Henry Kissinger.

- Decenio de 1980: lucha contrainsurgente en Centroamérica bajo el liderazgo de Ronald Reagan.

- Decenio de 1990 y primeros años del siglo XXI: destaca el impulso al libre comercio, en donde destaca la Iniciativa de las Américas y del ALCA bajo las administraciones de Ronald Reagan, George Bush padre (1988-1992), Bill Clinton (19922000) y George W. Bush (20002004).

Este itinerario histórico seguido por el gobierno estadounidense muestra una constante en las relaciones con la región. Es evidente el intervencionismo de esa potencia que considera a Latinoamérica como si fuese su patio trasero.

El último decenio del siglo XX Este dinámico decenio se caracterizó por la firma de varios tratados de libre comercio. Se destacan el 
Mercado Común del Cono Sur (MERCOSUR) iniciado en $1991 \mathrm{y}$ el Tratado de Libre Comercio de Norteamérica $^{3}$ (NAFTA, por sus siglas en inglés), firmado en 1994. Posteriormente, se firmaron varios tratados bilaterales de libre comercio entre las naciones americanas.

Este impulso de los tratados de libre comercio está influido por un aumento significativo del comercio mundial debido a la reducción del costo de los transportes y del avance de las telecomunicaciones. En fin, "La década de los noventa será recordada por la apertura al comercio y la reducción de barreras arancelarias y no arancelarias. La caída de los regímenes comunistas, la reunificación de las Alemania y la apertura de la economía china a la inversión extranjera, son todos legados de una década próspera para el comercio" (Robles, 2002).

3. El Tratado de Libre Comercio de Norteamérica (NAFTA) entró en vigencia el $1^{0}$ de enero de 1994. En negociaciones adicionales se incorporaron temas del comercio de servicios, compras del sector público y la solución de controversias. Para González (2000) el balance de cinco años de funcionamiento del NAFTA indica que la apertura no lo es todo y que hay otros elementos como el tipo de cambio y el proteccionismo que pueden afectar considerablemente.
Las Cumbres de Presidentes y las reuniones ministeriales Las Cumbres de Presidentes y las reuniones ministeriales se han realizado paralelamente. Los Presidentes se reunieron, en 1994, en la Primera Cumbre de las Américas y se llevó a cabo en Miami. Posteriormente, en abril de 1998, se realizó la Segunda Cumbre de las Américas, en Santiago de Chile y, finalmente, la Tercera Cumbre de las Américas se realizó en Quebec, en abril del 2001. Se han realizado reuniones entre los Ministros de Comercio, según el siguiente orden: Denver en 1995; Cartagena en 1996; Belo Horizonte en 1997; San José en 1998, Toronto en 1999 y Buenos Aires $^{4}$ en el 2001; y, Quito en octubre del 2002.

El Área de Libre Comercio de las Américas (ALCA)

Según Germán Gutiérrez (2001) el ALCA surgió como "iniciativa del gobierno de los Estados Unidos de George Bush padre, y tiene como antecedente el Tratado de Libre Comercio de Norteamérica (TLC o

4. La reunión realizada en Buenos Aires se caracterizó porque finalizó la etapa secreta de las negociaciones y se hizo público el primer borrador del ALCA (ver la página oficial del ALCA 2000) y se acordó que el segundo borrador se tendría para la reunión que se verificará en Ecuador, en octubre del 2002. 
NAFTA) entre México, Canadá y Estados Unidos, que entrara en vigencia en el año 1994. El ALCA fue concebido como un proyecto de extensión del TLC para el conjunto del Continente" (Gutiérrez, 2001:26).

La Cumbre de las Américas de 1994 en Miami

Asistieron 34 Jefes de Estado del continente que representaban a una población de 800 millones de personas y un Producto Nacional Bruto (PNB) conjunto de US\$ 11 trillones. El titular del gobierno cubano, Fidel Castro, no participó.

Áreas y líneas de trabajo de la declaración

En la Cumbre se aprobó una Declaración y un Plan de Acción. Se estipularon (Murillo, 2000) líneas de trabajo sobre 23 temas, agrupados en cuatro grandes áreas:

1. Preservación y fortalecimiento de la Comunidad de Democracias. En esta área se ubican los siguientes temas: el fortalecimiento de la democracia, la promoción y protección de los derechos humanos, el fortalecimiento de la sociedad y de la participación comunitaria, la promoción de los valores culturales, la lucha contra la corrupción y el problema de las drogas ilícitas y delitos conexos, la eliminación de la amenaza del terrorismo nacional e internacional y el fomento de la confianza mutua.

2. Promoción de la prosperidad, mediante la integración económica y el libre comercio. En esta área se encuentra el ALCA pero hay otras iniciativas de integración como son: el desarrollo y la liberación de los mercados de capital, la infraestructura hemisférica, la cooperación energética, las telecomunicaciones y la infraestructura de la información, la cooperación en ciencia y tecnología y el turismo.

3. Erradicación de la pobreza y la discriminación en el hemisferio en donde se consideran aspectos como: el acceso universal a la educación, el acceso equitativo a los servicios básicos de la salud, el fortalecimiento del papel de la mujer en la sociedad, el fomento de las microempresas y pequeñas empresas, y los Cascos Blancos (cuerpos para casos de emergencia).

4. Garantía del desarrollo sostenible y la conservación del medio ambiente para las generaciones futuras en donde se establecieron tres alianzas en los ámbitos del uso sostenible de 
la energía, la biodiversidad y la prevención de la contaminación.

En la segunda área se acordó, como meta principal, que el ALCA se iniciaría en diciembre del año 2002 (aunque posteriormente se fijó su inicio para el 2005). Se definieron como criterios generales el cumplimiento de las reglas y disciplinas multilaterales derivadas del GATT y de la Organización Mundial de Comercio (OMC) y la compatibilidad entre las políticas de liberalización comercial y las ambientales, así como la observancia y promoción de los derechos de los trabajadores. Se indicó también el aprovechamiento de los acuerdos comerciales vigentes y la adopción de medidas en cada país para el cumplimiento del plan de acción. Se estableció también un apoyo a las economías más pobres.

Luego, en la Segunda Cumbre de Presidentes, se retomaron esos temas y se formularon planes de acción, ya fuese por iniciativas de cooperación o iniciativas propiamente comerciales. Sin embargo, los elementos enumerados y descritos han sido objeto de poca atención; lo social se ha subordinado a lo estrictamente comercial.
Las proyecciones de un acuerdo

Los promotores del acuerdo y sus defensores señalan que el acuerdo permitirá una mayor competencia y eliminación de aranceles para el ingreso de productos y servicios a los países miembros. Consideran que se dará un incremento de los niveles de competitividad de la producción nacional para participar en el mercado del ALCA. Además, indican que se conseguirá una especialización en productos y servicios con valor agregado sobre los cuales un país posee ventajas competitivas. Todo ello redundará en un aumento en los volúmenes de comercio que elevará las ventas por exportaciones debido al acceso a un mercado de 800 millones de habitantes y a mejores precios de compra.

Se proyecta también una reducción de costos de producción y un incremento sustancial en los niveles de inversión tanto de los países del ALCA como también de otros países. Todo ello deberá estar avalado por el compromiso de los países miembros del ALCA para ofrecer garantía y seguridad a los inversionistas.

Se proyecta formar parte de un bloque comercial junto a los Estados Unidos que es una de las principales economías mundiales. Es- 
to disminuirá los niveles de riesgo, atraerá capitales externos y aumentará los niveles de empleo. Los consumidores nacionales se beneficiarán ya que accederán a una gran diversidad de productos y servicios ofrecidos por los países del hemisferio, a más bajos precios y con estándares elevados de calidad.

Quienes impulsan el acuerdo sostienen que el ALCA podrá tener efectos negativos a las empresas que no se reestructuren ni respondan a las nuevas exigencias del mercado. Pero también se plantean objeciones, ya que se requerirá iniciar adecuaciones empresariales y realizar investigaciones para esas adaptaciones. Ante las proyecciones optimistas, se contrasta la realidad de unos alcances modestos. Ante lo señalado, se indica que "Los resultados concretos en cuanto al cumplimiento de las modestas metas de la Cumbre de Miami han sido realmente decepcionantes, lo que refleja la falta de compromiso real sobre el tema. Solamente en ciertos compromisos de tipo comercial se ha avanzado" (Chiriboga 1999: 358-359). En fin, el ALCA “...representa el más importante acuerdo de integración regional firmado entre países desarrollados y no desarrollados con miras a establecer el libre flujo comercial entre sus economías" (CEPAL 1999:1). El problema radica en que no se com- prendan los intereses específicos que se ocultan con el ofrecimiento de metas que no serán prioritarias.

Las negociaciones y los actores

Las negociaciones del ALCA han sido conducidas, rotativamente, por las siguientes instancias:

- Una presidencia rotativa (por períodos de 18 meses).

- Un Comité de Negociaciones Comerciales, compuesto por los viceministros del comercio.

- Nueve grupos de negociación por temas que, a la fecha del presente estudio, la presidencia distribuía así:

Acceso a mercados (Argentina), Inversiones (México), Servicios (CARICOM), Compras del sector público (Costa Rica),

Solución de controversias (Paraguay),

Agricultura (Guatemala),

Propiedad intelectual (Estados Unidos),

Subsidios, antidumping y derechos compensatorios (Perú), Política de competencia (Colombia).

- Un Comité de Asistencia Técnica, compuesto por la Organización de Estados Americanos (OEA), el Banco Interame- 
ricano de Desarrollo (BID) y la Comisión Económica para América Latina (CEPAL).

- Un Comité de la Sociedad Civil, en el que participan sólo representantes oficiales.

El proceso de negociación del ALCA, en sí mismo, se encuentra a cargo de los Ministros de Comercio de los 34 países. Ellos dirigen y orientan el desarrollo del acuerdo y tienen la supervisión final de las negociaciones según criterios de rotación por acuerdo tomado en San José en marzo de 1998. El organigrama del ente negociador se encuentra en la Figura 1. Para Fernando Vallespín una de las dificultades actuales de la democracia radica en lo que denomina la "tecnocratización de la política" en la cual un número creciente de decisiones se apoya en el "conocimiento experto" que tiende a suplantar la discusión y el debate en nombre de la "decisión necesaria" (Vallespín 2000:178). Con ello se argumentan conocimientos morales superiores que se alejan incluso del interés público.

\section{a) La etapa de las negociaciones secretas}

Las negociaciones del ALCA fueron conducidas en secreto pero siempre han mantenido representantes de corporaciones que aconsejan a los negociadores y les ayudan a definir las reglas. Se eviden- cia un privilegio a los derechos del inversionista que permite incluso a las grandes empresas demandar los gobiernos por discriminación cuando obstaculicen sus inversiones (Ver Gutiérrez 2001:28). En la Segunda Cumbre de los Pueblos de las Américas en Quebec, en su declaración del 19 de abril de 2001, se cuestionó el proceso y se indicó que "Ni los pueblos de la región, ni el conjunto diverso de organizaciones sindicales y sociales, ni los parlamentos han podido participar en los debates ni conocer el detalle de la marcha de los acuerdos" (Ver Gutiérrez 2001:26). Finalmente, el secreto fue eliminado en la Reunión Ministerial de Buenos Aires, en el 2002, y el texto se encuentra disponible en la página web del ALCA (2002).

\section{b) La difusión de un acuerdo entre corchetes}

Los corchetes en el borrador del texto significan que, sobre esos textos, los 34 países no han logrado un consenso. Todos los países tienen el derecho de presentar a las diferentes mesas de negociación los textos que consideren relevantes para el avance del proceso. Si hay desacuerdo se coloca entre corchetes. Si posteriormente se alcanza un consenso, los corchetes se remueven. Si no se alcanza consenso, la propuesta puede ser retirada del texto. 
ESPIGA

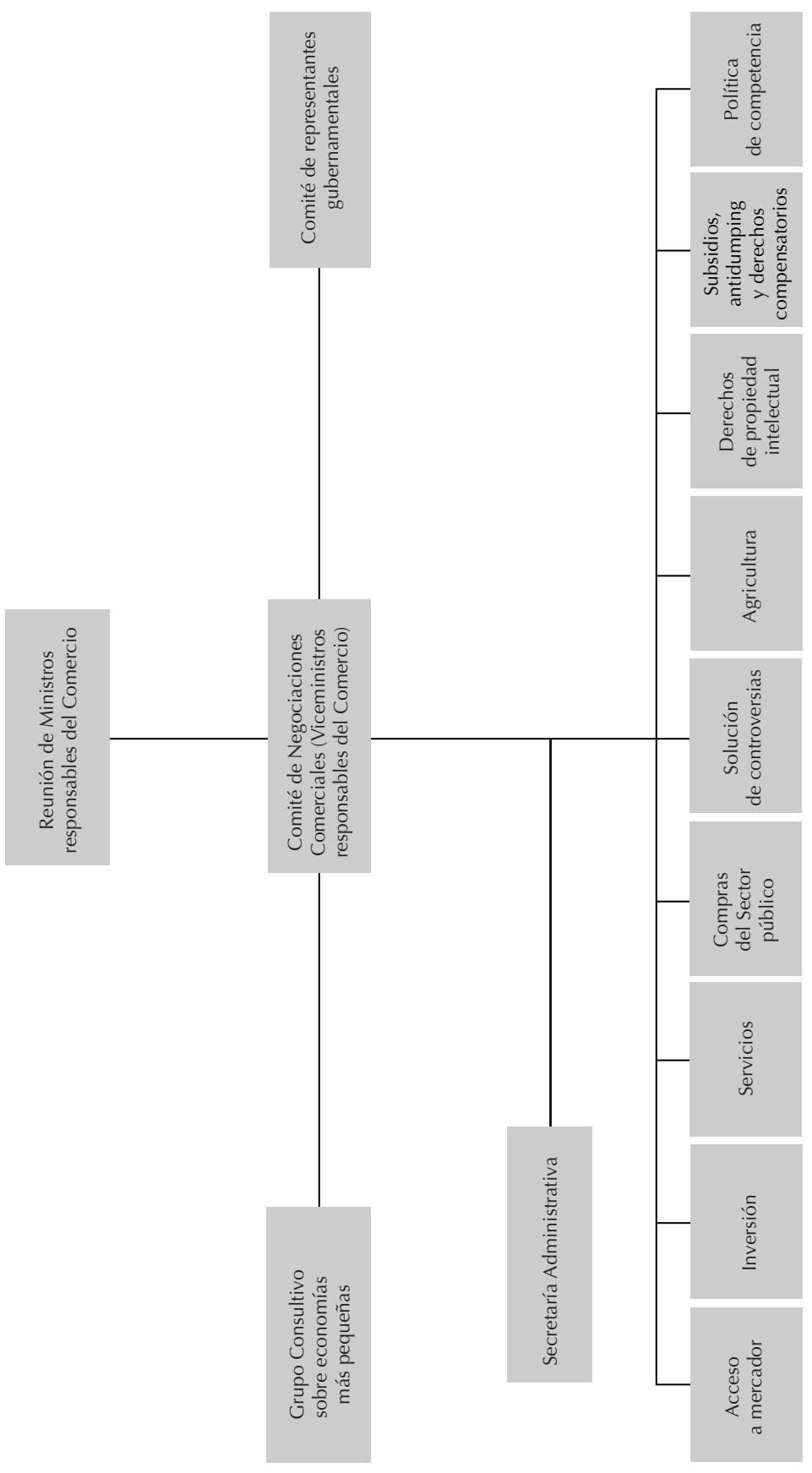

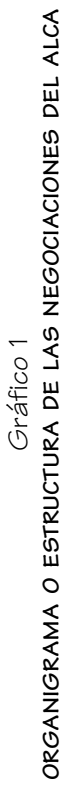

El área de libre comercio de las Américas 
c) Intereses y rivalidades de los grandes actores regionales

Para comprender la dimensión política del proceso de negociaciones es oportuno analizar el papel de los actores involucrados.

1. Estados Unidos. Promueve el proceso del ALCA pero ha tenido problemas ya que el Ejecutivo no ha conseguido la autorización del Congreso de la denominada "fast track" o vía rápida. El Ejecutivo puede negociar pero el Congreso puede modificarlo todo. Recientemente, (La Nación, 2002) se indicó: "El Senado de los Estados Unidos aprobó ayer una enmienda al proyecto de ley de Autoridad de Promoción Comercial (TPA) antes llamado "vía rápida", que reduciría la capacidad del presidente George W. Bush para negociar acuerdos comerciales." Lo anterior implica una limitación para las aspiraciones de Bush y de las grandes empresas transnacionales estadounidenses.

Hay que tener presente que la sociedad estadounidense posee gran influencia en los integrantes del Congreso y plantean abiertamente sus exigencias, lo cual retrasa el accionar estadounidense. Para algunos autores es visto incluso como una falta de liderazgo. Salazar
Xirinachs, por ejemplo, llega incluso a considerar beneficioso que el gobierno de los Estados Unidos llegue a obtener el fast track para negociar con autoridad y mantener liderazgo (Salazar 2001:300).

El sector agrícola estadounidense es el más protegido y subsidiado del mundo. El 3 de mayo del 2002, por ejemplo, se aprobó un subsidio de seis años a los agricultores por un monto de US\$180 billones (Becker 2002). El ALCA les exigiría una apertura en la cual no están interesados. El ALCA posee una fuerte oposición dentro de Estados Unidos por parte del sector no internacionalizado de la industria que, según Katz, perdería posiciones en el acuerdo.

2. Canadá. Le interesa diversificar sus exportaciones y quitarse el peso que los Estados Unidos tiene sobre su economía (cerca del 80\%). El gobierno canadiense está muy interesado en comerciar con América del Sur, Centroamérica y el Caribe. Ha sido un facilitador en las negociaciones. Tiene credibilidad, liderazgo y capacidad técnica para impulsar las negociaciones.

3. Chile. Unilateralmente está muy interesado en el ALCA y en acceder al mercado esta- 
dounidense y por ello mantiene una actitud activa y constructiva.

4. México. Cuenta ya con el acceso al mercado estadounidense y por ello el ALCA es una especie de obstáculo para los mexicanos ya que el MERCOSUR podría ser un fuerte competidor. México está en el ALCA pero con pasividad. Con la experiencia del NAFTA ha establecido tratados con otros países.

5. Comunidad Andina (CAN). Junto con Centroamérica es la región con países más frágiles. En Ecuador, Perú, Colombia y Venezuela se tiene una gama de problemas que van desde los enfrentamientos (Ecuador y Perú), pasando por la guerrilla y el narcotráfico (Colombia) hasta la política (Venezuela). Las desigualdades les impiden avanzar en los procesos de integración comercial. Se acercan al MERCOSUR para hacer un bloque más fuerte ante los Estados Unidos.

6. Mercado Común del Cono Sur (MERCOSUR). Conformado en 1995 por la República Federativa de Brasil, la República Argentina, la República del Paraguay y la República Oriental del Uruguay. Es el otro gran actor con papel decisivo en el proceso. Incluyó el tema agrícola en las negocia- ciones del ALCA a pesar de la oposición de Estados Unidos. Al MERCOSUR le interesa el ALCA pero busca consolidar primero su mercado, acercar socios fuertes y ganar tiempo para las negociaciones finales con Estados Unidos. Negociar despacio, con paciencia y lentitud. Para Katz "es indudable que toda la artillería de Estados Unidos está dirigida contra Brasil que detenta el mercado más apetecido y el conglomerado industrial más autónomo de las corporaciones norteamericanas" (Katz, 2002). La actual crisis argentina va a conducir a un nuevo enfoque de la integración. Para Katz, la intención estadounidense con el ALCA es fracturar al MERCOSUR.

7. Mercado Común del Caribe (CARICOM). Región muy particular que ha solicitado trato preferencial y fondos de ayuda. No le han concedido sus peticiones, sino que se atenderían cuando se inicie el proyecto integrador.

8. Mercado Común Centroamericano (MCC) o Centroamérica. Sus gobiernos muestran interés por la apertura y la promoción de las exportaciones. Han iniciado varios procesos conducentes a la firma de tratados de libre comercio con México, Chile, República Dominicana, Trinidad y Toba- 
go y Canadá. Están muy interesados en un tratado de libre comercio con Estados Unidos, su principal socio comercial. En el pasado, gozaron de los beneficios de la Iniciativa de la Cuenca del Caribe (ICC).

También se apunta a considerar dos círculos de influencia de los actores (Gráfico 2). El primer círculo lo determinan las dirigencias gubernamentales, la tecnoburocracia ministerial, particularmente de hacienda, finanzas, comercio y relaciones exteriores y, por supuesto, los sectores empresariales. Se aglutina alrededor de seis núcleos y su discurso gira en torno al libre comercio. El segundo círculo está conformado por organizaciones sociales, partidos políticos, organizaciones no gubernamentales, etc. Su núcleo son los Parlamentos y las instancias alternativas (sociedad civil). Su discurso gira en torno a la política social y los derechos humanos, la justicia económica, los derechos políticos y el desarrollo sostenible.

Entre los actores resaltan las diversidades.

- Extensión y población: Brasil, por un lado, con un área de 8,5 millones de $\mathrm{km}^{2}$ y una población de 166 millones y Santa Lucía, por otro, con $612 \mathrm{~km}^{2}$ y 140 mil personas.
- Generación de riqueza: Estados Unidos, en un extremo, con un PIB per cápita anual de $\$ 24000$ y Nicaragua, en el otro extremo, con \$357.

- Índice de Desarrollo Humano (IDH): Canadá (IDH de 0,936 y en el puesto 3) y Costa Rica (IDH de 0,821 y en el puesto 41) son países con alto desarrollo humano; Brasil (IDH de 0,750 y en el puesto 69) y Perú (IDH de 0,743 y en el puesto 73) clasifican como naciones con desarrollo humano medio; y Haití (IDH de 0,467 y en el puesto 134) es un país con bajo desarrollo humano del total de 162 países (PNUD 2001:145 y ss.).

- PIB: Latinoamérica y el Caribe juntos representan solamente el 20\% del PIB de Estados Unidos y Canadá juntos. Por ello, incluso en los defensores del ALCA, se advierte que "Todas estas diferencias, constituyen obstáculos nada despreciables, que requieren de visión y de responsabilidad para poder ser superados" (Murillo 2000:576).

En las negociaciones del ALCA no se puede perder de vista la existencia de un intento de acercamiento de América Latina con la Unión Europea, aspecto que es mirado con recelo por Estados Unidos. En la reciente Cumbre Unión Europea-América Latina, entre 48 Presidentes, se encontró un am- 


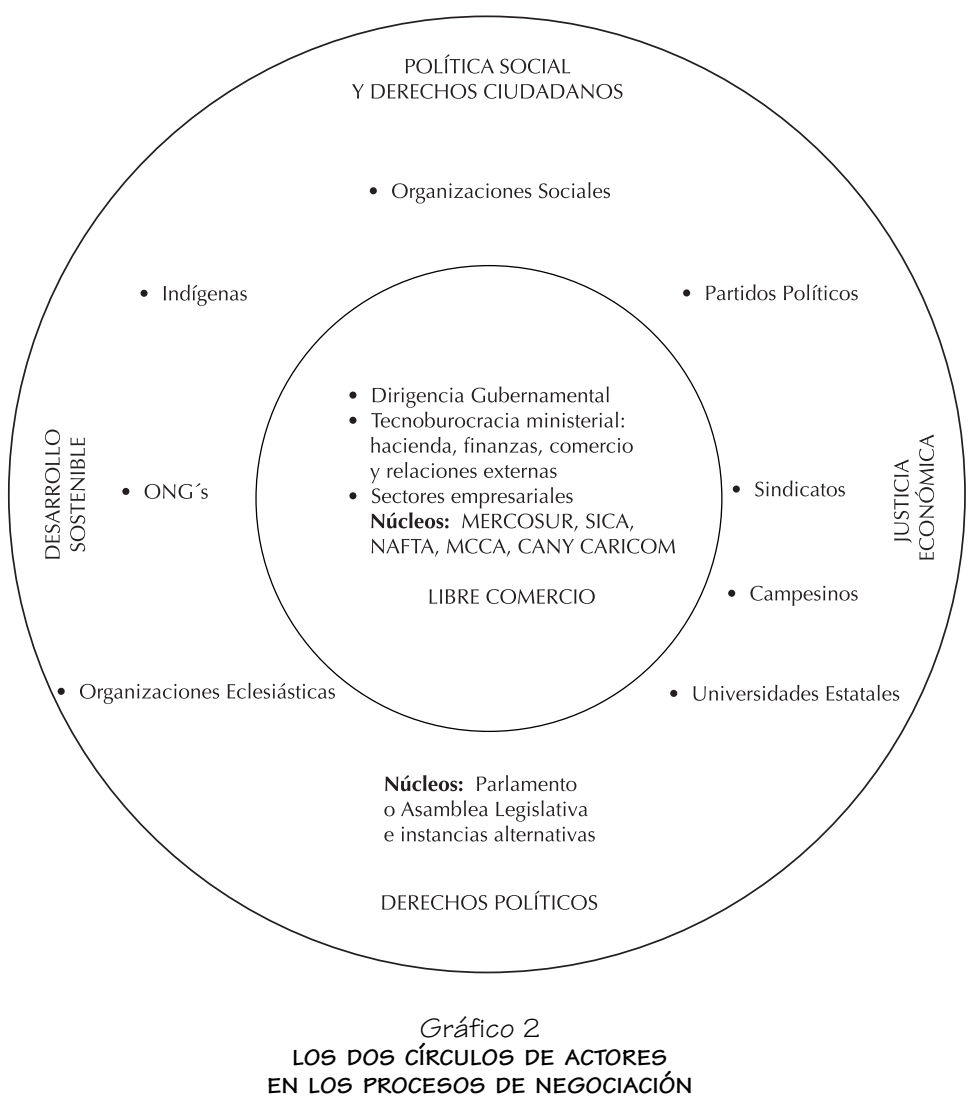

biente poco propicio para los tratados de libre comercio. En el periódico español La Vanguardia se indicó: "La Cumbre de Madrid, en definitiva, es el encuentro de dos mundos distintos, aunque unidos por vínculos de historia, de valores compartidos y de mutuos intereses. La Unión Europea es hoy día uno de los dos más ricos escenarios del mundo, donde la redistribución social es una de sus señas más características. Por el contrario, América Latina y el Caribe, con unos
200 millones de personas que viven debajo del umbral de la pobreza, configuran una región en la que el reparto de la renta es el más desigual del mundo" (La Vanguardia, 2002).

Pero ese no es el único problema. Los europeos "predican pero no reparten trigo". Sus exigencias se orientaron a pedir aperturas aduaneras y a comprometer a los gobiernos latinoamericanos en la lucha contra el terrorismo (muy similar al 
discurso estadounidense). El condicionamiento exigido por la Unión Europea implicó un viraje en su posición hacia América Latina (Mayorga, 2002) y se llegó a denominar como la cumbre de la vergüenza (Garnier, 2002). Los europeos resultan igual de proteccionistas que los estadounidenses y tampoco abren sus fronteras a los productos agrícolas latinoamericanos y mucho menos dejan de subsidiar a sus agricultores. Para Fernando Henrique Cardoso, presidente del Brasil, las grandes potencias se encuentran movidas por el miedo y sustituirán la esperanza de sus agendas y se obsesionarán únicamente con el tema de la seguridad (Sen, 2002).

\section{Grado de preparación de Costa Rica para participar en el ALCA}

En muchos sectores se afirma que Costa Rica no ha aplicado en la práctica una estrategia coherente para enfrentar su inserción en la economía internacional. Según el Programa de las Naciones Unidas para el Desarrollo (PNUD 2001:167) se desea impulsar un regionalismo abierto pero son evidentes los rezagos para participar en áreas muy competitivas. Para este organismo tampoco existen incentivos para aumentar la competitividad de las empresas.
En Costa Rica se aprobó el Decreto Ley N. ${ }^{\circ} 8056$, del 7 de diciembre del 2002, que se denomina "Ley para las negociaciones comerciales y la administración de los Tratados de Libre Comercio, acuerdos e instrumentos del comercio exterior". Este decreto indica:
"Artículo 1. La participación del país en los procesos de inserción en el comercio exterior debe darse en un ambiente de seguridad, confiabilidad y transparencia, en forma tal que por medio del co- mercio exterior pueda beneficiarse la sociedad en su conjunto, se pro- curen las mejores y mayores opor- tunidades para que los sectores productivos aprovechen al máxi- mo sus relaciones comerciales con el resto del mundo y los consumi- dores puedan obtener mayores op- ciones para satisfacer sus necesi- dades.
Artículo 2. Decláranse de interés público los procesos de negocia- ción comercial mediante los cua- les el país procura facilitar su in- serción en los mercados del co- mercio internacional."

Puede notarse una preocupación por mantener un clima democrático y participativo en el proceso de negociaciones. Sin embargo, el desconocimiento y una buena dosis de ingenuidad impera frente a esta temática. 
Para evaluar el grado de preparación del país para insertarse en la economía internacional se determinó el empleo de indicadores agrupados en tres conceptos: condiciones de elegibilidad, grado de preparación estructural y grado de preparación de políticas. Todo ello según sugerencias de la CEPAL y adaptadas para Costa Rica por el Proyecto Estado de la Nación. Es, básicamente, una comparación del país con respecto a los mejores indicadores en países de América con los cuales Costa Rica tendrá que competir en el ALCA. Para el PNUD, hay avances en los indicadores de elegibilidad. El grado de preparación estructural muestra un bajo grado. Pero es preocupante el grado de preparación de políticas. Concluyen que "resulta imperativo profundizar esfuerzos en los sectores público, empresarial y laboral, con el propósito de generar condiciones que favorezcan la competitividad sistémica del país y, particularmente, de las pequeñas y medianas empresas costarricenses" (PNUD 2001:170).

En un informe de la Comisión Económica para América Latina y el Caribe (CEPAL) se sostiene que "en la mayoría de los países los temas recién se están discutiendo y que falta mucho camino por recorrer si se pretende apoyar eficazmente el aumento de la competitividad y la productividad de las empresas" (CEPAL 1996:3).
Para ello consideran que el grado de preparación debe incluir criterios como: elegibilidad, orientación de las políticas, estructura económica y vulnerabilidad en términos comparativos (Ver Cuadro 3.20 en PNUD 2001:168-169).

Los indicadores son:

A. Indicadores de elegibilidad

A.1 Índice de precios al consumidor.

A.2 Saldo fiscal del Gobierno Central.

A.3 Saldo en cuenta corriente de la balanza de pagos.

A.4 Estabilidad del tipo de cambio nominal.

B. Grado de preparación estructural.

B.1 Estructura económica y sectorial.

B.1.1 Profundidad financiera.

B.2 Inserción internacional (diversificación y dinamismo exportador).

B.2.1 Grado de participación en las importaciones de Estados Unidos.

B.2.2 Porcentaje de exportaciones de manufacturas del total de exportaciones.

B.3 Recursos Humanos.

B.3.1 Mano de obra empleada en sectores modernos (no agrícola). 
C. Grado de preparación de políticas.

C.1 Política macroeconómica.

C.1.1 Ahorro corriente del Gobierno Central.

C.1.2 Crédito del sector privado/crédito interno.

C.1.3 Tasa de interés real (pasiva).

C.1.4 Impuestos comercio exterior/ingresos tributarios.

C.1.5 Reservas internacionales netas/meses importados.

C.2 Política de transformación productiva.

C.2.1 Gasto público en educación.

C.2.2 Alumnos/maestro en primaria.

C.3 Vulnerabilidad comercial.

C.3.1 Exportaciones de prendas de vestir a Estados Unidos.

C.4 Vulnerabilidad macroeconómica.

C.4.1 Total deuda externa/exportaciones de bienes y servicios.

C.4.2 Saldo comercial.

C.4.3 Intereses totales deuda externa/exportaciones de bienes y servicios.

C.4.4 Ahorro doméstico.

Cada aspecto es calificado como "muy satisfactorio", "satisfactorio" o "no satisfactorio". Para el caso costarricense, los satisfacto- rios se obtienen en los incisos B.2.2, B.3.1, C.1 y C.4.1. Los retos en este campo son numerosos, con mayor razón si la principal actividad es la agricultura y si se toma en cuenta el lento avance hacia la industrialización. Además, el sector servicios se caracteriza por su escaso desarrollo o tendencia a la informalidad.

\section{La reacción ante (contra) el ALCA}

Las reacciones son ante y contra el ALCA. Incluso se puede agregar una tercera reacción incondicional a favor del ALCA mostrada por los seguidores del llamado globalismo pop. En esta sección se recogerán tres tipos de reacciones: la oficial y optimista, la reacción académica y algunas posiciones representativas.

\section{La reacción oficial}

y optimista

Para Carlos Murillo, exviceministro de Comercio Exterior de Costa Rica, las cifras hablan por sí solas y sostiene que "los avances en materia de integración y comercio desde la Cumbre de Miami en diciembre de 1994 no se limitan por supuesto a la preparación para las negociaciones para el ALCA. Más bien, lo más notable de lo que ha ocurrido hasta ahora en el hemisferio, lo cual alimenta la espe- 
ranza de que el ALCA sea un proyecto politica y económicamente viable, es que la liberalización comercial ha demostrado su efectividad en producir resultados positivos y concretos, lo que a su vez ha dado nuevos bríos a una verdadera ola de acuerdos bilaterales y subregionales" (Murillo, 2000:572).

Esta visión optimista y acrítica muestra, con frecuencia, la constante que ha caracterizado a los llamados negociadores. Sugieren que se mantenga y fomente con firmeza los procesos de apertura y la negociación de tratados bilaterales y subregionales. "No debemos dejar -concluye Murilloque las coyunturas, obstáculos o incertidumbres de corto plazo detengan la integración económica y las prioridades del largo plazo" (Murillo, 2000:572). Consideran que los recursos destinados a la protección perpetúan la pobreza y condenan al subdesarrollo; que la apertura implica mayor disponibilidad de productos, y que la competencia desleal se presenta no cuando un producto importado se vende a un menor precio sino cuando el precio de un bien es menor a su costo de producción por la existencia de subsidios (Robles, 2000:XI). Proponen la reconversión productiva y ocupacional incluso para los pequeños agricultores y campesinos para quienes se sugiere que " Hay que reconocer que tal vez la solución para este grupo no pase precisamente por la agricultura!" (Trejos, 1999:77). Otros afirman que estas negociaciones se llegarán a implementar en el año 2005 o incluso antes (Salazar, 2001:300).

Sin embargo, como se ha indicado en secciones anteriores, estos negociadores (¿promotores?) hasta hace muy poco tiempo han dejado la fase secreta de las negociaciones y al enfrentar a la opinión pública y a las otras fuerzas políticas su discurso se ha modificado y tenderá a modificarse aún más cuando tengan que conducir las negociaciones ante los parlamentos y sean confrontados por la opinión pública, los grupos afectados y el público en general, en caso de que reaccionen.

En la línea oficial, se parte de la base del Decreto Ley número 8056 denominado "Ley para las negociaciones comerciales y la administración de los tratados de libre comercio, acuerdos e instrumentos del comercio exterior" del 7 de diciembre del 2000. En el decreto se indica:

"Artículo 1. La participación del
país en los procesos de inserción
en el comercio exterior debe dar-
se en un ambiente de seguridad,
confiabilidad y transparencia, en 
forma tal que por medio del comercio exterior pueda beneficiarse la sociedad en su conjunto, se procuren las mejores y mayores oportunidades para que los sectores productivos aprovechen al máximo sus relaciones comerciales con el resto del mundo y los consumidores puedan obtener mayores opciones para satisfacer sus necesidades.

Artículo 2. Decláranse de interés público los procesos de negociación comercial mediante los cuales el país procura facilitar su inserción en los mercados del comercio internacional."

El marco legal creado permitirá un interesante juego político en la

5. Se informó que ese tratado permitirá el ingreso inmediato a Canadá del $86 \%$ de los productos costarricenses. Se mostraron satisfechos los sectores gubernamentales, industriales, cañeros y horticultores. La principal oposición provino de los paperos de la zona norte de Cartago quienes alegaron que el ingreso de la papa prefita canadiense les causará muchos perjuicios. Según información suministrada por la prensa (Venegas, 2002), "el Poder Ejecutivo se comprometió con el sector [papero] a desarrollar una estrategia que le permita a ese sector enfrentar la competencia externa." Se creará una base nacional de semilla certificada al alcance de los productores, se les dará capacitación en nuevas tecnologías y se controlará en las aduanas el ingreso de cargamentos de papa subfacturada. El monto de la ayuda asciende a $\Varangle 2.000 .000 .000$.00. El diputado que se
Asamblea Legislativa cuyos resultados se comenzaron a ver a mediados del 2002 cuando se aprobó el Tratado de Libre Comercio Costa Rica-Canadá con el apoyo de 53 diputados a favor y uno en contra. $^{5}$

Algunas reacciones académicas frente al ALCA

Consiste en conjuntos de reflexiones planteadas en los ámbitos académicos. No existe unanimidad pero se rescatan reflexiones elaboradas en un marco de análisis objetivo y crítico. Es frecuente que se formulen interrogantes entre las que destacan:

opuso, Gerardo Vargas Leiva del Partido Acción Ciudadana, argumentó que el monto no es suficiente para atender la reconversión productiva que se requiere. En el periódico $\mathrm{La}$ Nación del mismo día de la votación, con el sugestivo título de "A votar, jcarajo!", se invitó a los diputados a legislar para todos los sectores y no solo para uno. Se argumentó que "podríamos llegar a tener un país completo beneficiado con la firma del TLC con Canadá." (Vega, 2002). Afirmó también que "El TLC con Canadá es parte de la globalización. Tener una visión global es tener una visión optimista. El libre comercio significa que el capital que genera empleo puede fluir libremente hacia donde pueda ser más productivo y no hacia donde los gobiernos y los trabajadores crean que deba encauzarse." Estamos notificados, ¡carajo! 
- ¿Qué papel jugará lo económico en la futura evolución del ALCA? ¿Será lo económico-comercial el papel dinamizador del proceso o serán elementos más políticos? Estos autores apuntan a realizar visiones interdisciplinarias que trasciendan los enfoques economicistas.

- ¿Es la especialización y el intercambio entre países el camino más adecuado para aprovechar las ventajas comparativas y competitivas? Se recomienda cautela ya que en ocasiones el comercio no ha sido el factor dinámico que se esperaba que fuese.

- ¿Hay ganadores y perdedores en el proceso integracionista? Ante la existencia de asimetrías recomiendan mecanismos de transferencia y de compensación para las economías que queden rezagadas.

- ¿Puede separarse los aspectos comerciales de los temas ambientales ${ }^{6}$ y laborales? Sostienen que hay peligros irremediables e inminentes; que las mediciones de pérdida o ganancia de puestos de trabajo no son confiables; que tampoco son confiables los estudios sobre la competitividad. Sostienen que en las relaciones en el campo comercial-ambientallaboral existen dudas razona- bles. Tanto la visión ambientalista como el fenómeno de la U invertida deben ser objetos de investigación. Igualmente se cuestiona la teoría del desborde. Se cuestiona entonces la insistencia en que primero es el desarrollo económico, luego vienen los aspectos sociales y después los ambientales. Sectores académicos consideran que esto no ha funcionado (De Camino, 1999:31).

- ¿Cómo promover la organización de los pequeños para participar adecuadamente en el proceso de apertura? Ante ello se recomienda prudencia debido a que habrá sectores fuertemente afectados.

Se reconoce que "la ciencia económica tiene limitaciones importantes, tanto desde el punto de vista teórico como

6. Para algunos autores la visión ambientalista de la relación entre el comercio y el manejo sostenible del ambiente ha sido normalmente una relación de antagonismo. La hipótesis es que el comercio (y la producción que se genera) se llevará a cabo en una forma sostenible $y$ depredadora. También que la tecnología puede ser valorada en términos de su capacidad para degradar y contaminar el ambiente. Propone conocer más las verdaderas relaciones entre producción, consumo, comercio y ambiente. Se cuestiona, eso sí, a quienes consideran que el ambiente sea algo accesorio y de lo cual se puede prescindir (Ver Aguirre 1999: 23 y ss). 
¿SP

instrumental para analizar fenómenos relativamente nuevos como los que plantea el ALCA" (Villasuso, 1999:13). Sostiene este autor que es posible que muchas de las preguntas que los formadores de política y tomadores de decisiones planteen a los académicos queden sin respuesta por la carencia de teorías verificables y falta de herramientas analíticas confiables. Por ello, desde este sector académico se insiste en un papel crítico en el análisis del ALCA.

\section{Algunas posiciones representativas}

Contrariamente a las versiones oficiales que miran con benevolencia al proyecto del ALCA las posiciones en la sociedad civil son muy definidas, en especial, desde la divulgación del borrador a finales del 2001. Las protestas y el rechazo se aceleraron a partir de la Tercera Cumbre de las Américas (Quebec, abril del 2001) pero ya se habían iniciado bajo la modalidad de cumbres paralelas como en Chile, cuando en 1998, al celebrarse la Segunda Cumbre de las Américas, se realizó la Primera Cumbre de los Pueblos de América que elaboró incluso un documento alternativo.

El rechazo al ALCA se ha complementado con un llamado a construir un esquema de integración hemisférica que garantice el desa- rrollo sustentable, promueva la justicia social y respete la soberanía de los pueblos.

Fidel Castro

y la diplomacia cubana

El Gobierno cubano y su diplomacia han mostrado una actitud de oposición sistemática a todo proceso integrador. Sin embargo, han dado algunos signos de apertura comercial y diplomática, aunque a principios del 2002 se dio un quiebre significativo ante la crisis entre Cuba, México y Uruguay. En el discurso pronunciado ante la Conferencia para el Financiamiento del Desarrollo en Monterrey, México, el presidente cubano Fidel Castro indicó "El proyecto de consenso que se nos impone por los amos del mundo en esta conferencia, es el de que nos resignemos con una limosna humillante, condicionada e injerencista. Hay que repensar todo lo creado desde Bretton Woods hasta hoy. No hubo entonces verdadera visión de futuro. Prevalecieron los privilegios y los intereses del más poderoso" (Castro, 2002). En ocasiones, la posición del gobierno cubano ocasiona perplejidad en la región latinoamericana debido a su naturaleza de proyecto político alternativo al capitalismo. No han faltado incluso las tensiones y la desconfianza mutua. Sin embargo, hay que reconocer que en el caso espe- 
cífico del ALCA y de las relaciones con los organismos financieros internacionales, la posición del gobierno cubano ha sido constante, por un lado, y muy crítica, por otro lado.

\section{Foro Andino}

Es un foro que se conformó el 15 de abril del 2002, en la ciudad de Quito, para formar una fuerza de lucha global en pro de la solidaridad y la oposición a las políticas neoliberales. Se integraron más de cien delegados provenientes de Perú, Bolivia, Colombia, México, Uruguay, Suecia, Francia y Ecuador. Su principal mecanismo de comunicación es la red Internet. Para ellos el ALCA es un plan elaborado e impuesto por el Banco Mundial, el Fondo Monetario Internacional, la Organización Mundial de Comercio y los Estados Unidos para beneficiar a empresas transnacionales. Sostienen que mientras esto ocurre millones de hombres y mujeres viven en la miseria y pierden todo derecho a vivir con dignidad. Su lema es "No al ALCA, otra América es posible, otra integración es posible."

Partido Socialista-Frente Amplio del Ecuador

Para Manuel Salgado Tamayo, Secretario General de ese partido, el
ALCA es entendido como una continuación de las políticas estadounidenses para América Latina desde el siglo XIX. El ALCA es percibido dentro de los problemas de seguridad estadounidense y su guerra contra la cocaína. Consideran que Estados Unidos criminaliza todo el proceso integracionista y vacía de contenido el problema de la injusticia, el desarraigo, la falta de oportunidades, la miseria, los privilegios, entre otros (Salgado, 2002).

Indica Salgado que el actual esquema del ALCA beneficia principalmente a las clases dominantes, a las grandes empresas transnacionales y a la burguesía monopolista norteamericana. Fijan su mirada en los cuestionamientos al ALCA realizados por los sindicatos estadounidenses. No ocultan su admiración al gobierno y a los diplomáticos cubanos y le asignan autoridad moral debido a la crítica sistemática y apasionada al expansionismo capitalista. Sostiene Salgado que, después de que el borrador se hizo público, se evidencia que el ALCA:

1. Significa la postergación de la democracia participativa y el respeto a los derechos humanos.

2. No es un acuerdo de libre comercio sino una combinación 
-siguiendo a Chomsky- de liberalización con proteccionismo (Gutiérrez, 2002:28).

3. No es un mecanismo para erradicar la pobreza.

4. No garantiza el desarrollo sostenible.

5. No elimina la discriminación, el racismo y la xenofobia.

6. Que los jóvenes pueden esperar del ALCA solamente desempleo, subempleo, ampliación de flujos migratorios, educación transformada en negocio, pobreza y hambre.

En adición a lo anterior, Katz ha indicado críticas al capitalismo y la existencia de una ligazón directa entre el viejo sueño de la unidad latinoamericana y el establecimiento de nuevas formas de propiedad y gestión colectiva de la economía.

Foro Mundial Social

En su reunión denominada Porto Alegre II, realizada entre el 1 y el 5 de febrero del 2002, se convocó a los movimientos sociales para resistir contra el neoliberalismo, el militarismo y la guerra. Se hizo un llamado por la paz y la justicia social. Los dirigentes del Foro se autocalifican como un movimiento de solidaridad global, unido a la determinación para luchar contra la concen- tración de la riqueza, la proliferación de la pobreza y la desigualdad y la destrucción del planeta. Entre los mecanismos de acción sugieren protestas, amplias manifestaciones y plebiscitos contra el ALCA. Señala Petras (2002) que en ese Foro participaron unas 70000 personas entre reformistas, académicos, "oegeneros", dirigentes políticos, radicales del Movimiento Sin Tierra del Brasil, delegados del Partido de los Trabajadores del Brasil, representantes de partidos de izquierda, sindicatos, movimientos urbanos y grupos de solidaridad con diferentes composiciones sociales. La reunión terminó con una marcha no-oficial de 50000 participantes contra el ALCA. Según Petras, hay un fuerte movimiento anticapitalista que posee una agenda muy amplia apoyada en movimientos sociales radicales.

Con respecto a este mismo Foro, Inmanuel Wallerstein (2002) encuentra muchas fortalezas en ese movimiento pero también debilidades: falta de centralización y escasa tolerancia. Aunque esas debilidades pueden ser, a la vez, fortalezas. Les señala dos tareas: Primero, analizar hacia adónde va, estructuralmente, la economía capitalista mundial y cuáles son sus debilidades inherentes; y segundo, comenzar a delinear un orden mundial alternativo. 


\section{CONCLUSIONES}

1. Es preciso resolver y entender el papel de los Estados Unidos en el ALCA y sus intereses específicos. Estados Unidos mantiene hacia la región una agenda negativa enfatizada en el control del narcotráfico y el combate al "dumping". Para América Latina -no necesariamente sus gobernantes- su interés está centrado en aspectos positivos como la búsqueda de la equidad social pero esta agenda no ha sido prioritaria. La asimetría entre Estados Unidos y América Latina se ubica no solo en las estadísticas sino también en las prioridades y en el enfoque del proceso integracionista. Lo que Estados Unidos busca es una América Latina como pieza subordinada del escenario creado por ellos.

2. Las respuestas de los países americanos a los retos integracionistas están vinculadas a procesos políticos, sociales y económicos que se asocian a la consolidación de la paz, la búsqueda de sociedades más justas y el fortalecimiento de los regímenes democráticos. Estas aspiraciones no encuentran cabida en las prioridades comerciales de los Estados Unidos.
3. Es imprescindible la incorporación de más actores a los procesos de discusión y negociación y debe abandonarse, definitivamente, el carácter secreto y exclusivista de los negociadores ya que el proyecto pierde legitimidad incluso antes de ser discutido en los órganos políticos de mayor representatividad, como la Asamblea Legislativa, en el caso de Costa Rica. Desafortunadamente, los sectores políticos se caracterizan por su escasa crítica y por una buena dosis de oportunismo.

4. Las asimetrías en los países latinoamericanos no pueden obviarse. Los gobiernos deben tenerlas en cuenta en los procesos de negociación, de lo contrario pueden enfrentar problemas de gobernabilidad o destruir la esperanza de un desarrollo equitativo que se ha cifrado en la integración, el ALCA incluido. Los gobiernos deben trascender el marco del mercado y llegar a esferas e instrumentos de cooperación y solidaridad.

5. La sociedad civil exige compromisos en el campo social, la inclusión, los derechos humanos, los derechos laborales, los derechos de los indígenas, los pequeños productores, la erradicación de la pobreza, entre otros. La sociedad civil debe 
participar en la toma de acuerdos. Es necesaria la libertad de expresión y de crítica que conduzcan a planteamientos humanísticos. La investigación y la generación de pensamiento crítico sobre los alcances y las implicaciones de los procesos integracionistas deben considerar a los menos favorecidos en el proceso.

6. El desarrollo se percibe por la senda de la integración y la unión entre países que aprovechen las ventajas de la economía de mercado. Sin embargo, las uniones regionales deben hacerse en un marco auténtico de cooperación y beneficio mutuo. Un país como Costa Rica, no puede aislarse de los procesos de integración pero tampoco puede ser obligado a unirse por la fuerza, la prepotencia o el poderío que no contemplan el derecho a buscar sendas alternativas y que niegan la posibilidad de discutir o disentir.

7. Las negociaciones para la creación del ALCA no van por la senda correcta; sus beneficios se plantean solamente para ciertos sectores en detrimento de grandes masas de la población. Por ello, no se vislumbra su implementación en el horizonte de lo posible y menos en el horizonte de la justicia. Se cuestiona el culto al mercado y el abandono de la solidaridad. Ante ello, es preciso tener claridad sobre lo que se quiere: una sociedad en donde todos quepan, humanista, incluyente, solidaria y participativa.

\section{BIBLIOGRAFÍA}

Aguirre, Juan. (1999). "Medio ambiente, comercio y ALCA." En: Villasuso, Juan Manuel y Trejos Solórzano, Rafael (Editores). Comercio e integración en las Américas. San José: BID-INTAL, IICE-UCR, IICA, pp. 22-30.

Anderson, James. (1978). Public Policy-Making. New York: R.E. Krieger Publishing Co.

Área de Libre Comercio de las Américas. (2002). http://www.alca-ftaa.org

BECKER, Elizabeth. (2002). "House Passes the Farm Bill, Wich Bush Says He'll Sign." The New York Times on the web. 3 de mayo del 2002.

CAstro, Fidel. (2002). "El actual orden mundial y la Conferencia de Monterrey. Discurso pronunciado ante la Conferencia para el Financiamiento del Desarrollo en Monterrey, México." http://www.rcci.net/globalizacion/2002/fg226.htm

CEPAL-NACIONES UNIDAS. (1996). “La integración hemisférica: el grado de preparación en el istmo cenroamericano y la República Dominicana". Documento de distribución limitada. LC/MEX/1.305 del 31 de julio de 1996.

CEPAL-NACIONES UNIDAS. (1999). “La conformación del Área de Libre de las Américas (ALCA). Aspectos institucionales y comerciales". Documento de distribución limitada. LC/MEX/1.405 del 12 de octubre de 1999. 
Chiriboga, Manuel. (1999). "El ALCA en la mira de los actores sociales regionales: Opciones para una política social regional." En: Villasuso, Juan Manuel y Trejos Solórzano, Rafael. (Editores). En: Comercio e Integración de las Américas. San José: IICA, IICE-UCR e INTAL-BID, pp. 357363.

Colombia. Ministerio de Comercio Exterior. (2002). http://www.mincomex.gov.co/comercio/ALCA/preguntas.asp

Costa Rica. Poder Legislativo. (2000). Decreto Ley N. 8056 denominado "Ley para las negociaciones comerciales y la administración de los Tratados de libre comercio, acuerdos e instrumentos del comercio exterior." 7 de diciembre del 2000. La Gaceta, Diario Oficial del 15 de enero del 2001.

De Camino, Ronnie. (1999). "Ambiente, política y ALCA." En: Villasuso, Juan Manuel y Trejos Solórzano, Rafael (Editores). Comercio e integración en las Américas. San José: BID-INTAL, IICE-UCR, IICA, pp. 31-33.

FALLAS, Helio. (1999). "Apertura comercial y competitividad de la agricultura." En: Villasuso, Juan Manuel y Trejos Solórzano, Rafael (Editores). Comercio e integración en las Américas. San José: BID-INTAL, IICE-UCR, IICA, pp. 39-42.

FigueroA, Eugenio y Pasten Roberto. (1999). "Crecimiento y medio ambiente: ¿existe automatismo en la U invertida?" En: Villasuso, Juan Manuel y Trejos Solórzano, Rafael (Editores). Comercio e integración en las Américas. San José: BID-INTAL, IICE-UCR, IICA, pp. 43-49.

Foro ANDINO. (2002). Las Organizaciones del campo frente al Área de Libre Comercio de las Américas. (smd).

Foro Social Mundial. Porto Alegre II. (2002). "Convocatoria de los movimientos sociales. Resistencia contra el neoliberalismo, el militarismo y la guerra: por la paz y la justicia social. http://www.forumsocialmundial.org.br y www.portoalegre2002.org

GARNiER, LEONARDO. (2002). "La cumbre de la vergüenza." En: La Nación Digital. San José: 23 de mayo del 2002. http://lanación.cr.com

GonZÁlez, Adalberto. (2000). “El Tratado de Libre Comercio de Norteamérica (NAFTA)." En: Robles, Edgar (Editor). (2000). Centroamérica y la integración económica hacia el siglo XXI. San José: IICE, pp. 463498.

GutiérReZ, Germán. (2001). “El ALCA y la guerra antiterrorista de George W. Bush." En: Revista Pasos. San José: Editorial DEI, número 98.

KatZ, Claudio. (2002). "El abismo entre las ilusiones y los efectos del ALCA." En: Revista Realidad Económica. Argentina, (smd).

LA NACión. (2002). "Golpe comercial para Bush". San José: 16 de mayo del 2002, p. 27 a.

La Vanguardia. (2002). Cumbre UE-América Latina. El reto de Madrid. 18 de mayo del 2002. Disponible en http://www.telepolis.com / cgi-bin / reubica?i$\mathrm{d}=37493$ \&origen $=$ htmldigital

Lindblom, Charles. (1991). El proceso de elaboración de políticas públicas. Madrid: Ministerio para las Administraciones Públicas.

MAYORGA, Armando. (2002). "Europa condiciona un TLC." En: La Nación. San José: 18 de mayo 2002, p. 18.

MENY, Yves y Thoenig, Jean-Claude. (1992). Las políticas públicas. Barcelona: Ariel.

Murillo, Carlos. (2000). “Área de Libre Comercio de las Américas: Antecedentes, organización, estado actual, retos futuros, aspectos relevantes de las mesas de negociación del ALCA." En: Robles Cordero, 
Édgar. (Editor). (2000). Centroamérica y la integración económica hacia el siglo XXI. San José: IICE-UCR.

Petras, James. (2002). "Una historia de dos foros." http://www.forumsocialmundial.org.br/esp/balanco_JamesPetras_esp.asp

Programa de las Naciones Unidas para el Desarrollo. (2001). "Informe sobre Desarrollo Humano". Madrid: MundiPrensa.

Proyecto Estado de la Nación. (2000). "Estado de la Nación en Desarrollo Humano Sostenible: sexto informe 1999". San José: Proyecto Estado de la Nación.

Robles, Edgar. (2000). “Presentación". En: Robles, Edgar. (2000). Centroamérica y la integración económica hacia el siglo XXI. San José: IICE.

Salazar Xirinachs, José Manuel. (2001). "The FTAA Process: From Miami 1994 to Quebec 2001." (smd)

Salgado Tamayo, Manuel. (2002). "El Plan Colombia y el ALCA." (smd).

SEN, Cristina. (2002). La Vanguardia Digital, 18 de mayo del 2002. http://www.telepolis.com/

SubiRAts, Joan. (1992). Análisis de politicas públicas y eficacia de la administración. Madrid: Ministerio para las Administraciones Públicas.
TÓRTORA, Manuela. (1999). "Política social y ALCA." En: Villasuso, Juan Manuel y Trejos Solórzano, Rafael (Editores). Comercio e integración en las Américas. San José: BID-INTAL, IICE-UCR, IICA, pp. 385-393.

Trejos, Rafael. (1999). "Agricultura bimodal y apertura comercial." En: Villasuso, Juan Manuel y Trejos Solórzano, Rafael (Editores). Comercio e integración en las Américas. San José: BID-INTAL, IICEUCR, IICA, pp. 75-79.

VALLesPín, Fernando. (2000). El futuro de la política. Madrid: Taurus-Pensamiento.

Vega H., Allen. (2002). "A firmar, ¡carajo!" En: La Nación, 22 de julio del 2002, p. $18 \mathrm{~A}$.

Venegas, Ismael. (2002) "Aprobado el TLC con Canadá". En: La Nación, 23 de julio del 2002, p. 4A.

Villasuso, Juan Manuel. (1999). "Presentación." En: Villasuso, Juan Manuel y Trejos Solórzano, Rafael (Editores). Comercio e integración en las Américas. San José: BID-INTAL, IICE-UCR, IICA, pp. 9-14.

WALLERStein, Immanuel. (2002). "Porto Alegre 2002." http:/ /www.forumsocialmundial.org.br/esp/balanco_ImmanuelWallerstein_POS_esp.asp 